\title{
Big Data and its Applications in Supply Chain Management: Findings from a Delphi Study
}

\author{
Morten Brinch \\ University of Southern Denmark \\ mobr@sam.sdu.dk
}

\author{
Jan Stentoft \\ University of Southern Denmark \\ stentoft@sam.sdu.dk
}

\author{
Jesper Kronborg Jensen \\ University of Southern Denmark \\ jkrj@sam.sdu.dk
}

\begin{abstract}
Big data and its applications have increasingly received interest by both scholars and practitioners. However, there is still missing evidence regarding how big data is understood as well as its applications in supply chain management (SCM). Empirical contributions are especially limited. This study seeks to address this gap through an explorative Delphi study to understand the terminology of big data and its application in the SCM processes of sourcing, manufacturing, service, logistics, planning, and return. The findings reveal that big data is mostly concerned with data collection and logistics, service, and planning processes are the most applicable processes for deploying big data analytics in SCM. Furthermore, a range of applications have been identified and ranked within each process.
\end{abstract}

\section{Introduction}

The application of data and information flows has dominated supply chain management (SCM) practices for several decades, in which traditional business analytic methods have been applied to support decision-making. As technologies have evolved, they have increasingly enabled supply chains to capture, manage, and analyze data. The mobile internet, Internet of Things, advanced robotics, 3D printing, and RFID chips are just some of the technologies that can potentially disrupt the status quo and make supply chain practices remarkably different [19]. Embedded in these technologies are the ability to handle high volumes of diversified data that traditional information technologies are unable to process. This paradigmatic shift in data and information is referred to as big data, which enables new knowledge discoveries in business environments [6].

From a SCM perspective, big data can be utilized by various analytic procedures for descriptive, predictive, and prescriptive purposes that will help companies make more effective decisions for strategic and operational applications. But, it has been revealed that a gap between big data theory and supply chain practices exists, and many questions are still unanswered, e.g., how to leverage big data volumes and unstructured data [20]. Furthermore, it has been specified that big data analytics can be applied across the supply chain involving sourcing, manufacturing, distribution, and marketing [27]. Even though businesses have positive sentiments about big data, the business literature on big data is rather fragmented and lacks empirical contributions [11]. For instance, a recent literature review on big data in SCM asserted that contributions are mostly conceptual and, to a large extent, lack theoretical and methodological rigor [2]. To address this theoretical gap and to guide SCM practitioners, there is a need for a more thorough understanding on how big data can increase the value generation of SCM processes. More specifically, recent papers have suggested future research topics on e.g., how to integrate big data in business analytics [36], how to capture value from big data using new theories that encompass cross-functional facets [10], and how to understand what kind of supply chain questions can be addressed by big data [28]. To summarize, the potential benefits of utilizing big data analytics in SCM are high, but its application is rather elusive [28] and lacks empirical research and practical insights [38].

The purpose of this article is two-fold. First, the purpose is to increase the overall understanding of big data in SCM context by exploring practical insights into the definition of big data, which could align practitioners' and scholars' views on big data. The second purpose is to explore and empirically identify possible areas of application for big data in SCM by classifying and ranking the application of big data within SCM processes.

The article continues with the underlying theoretical foundation for this study, followed by an explanation and argument for our choice of method. Then the empirical findings are presented and discussed against existing theory. The paper ends with a conclusion and suggestions for future research. 


\section{Relevant literature}

This section describes relevant literature to frame the phenomenon in focus in this paper and is organized into three subsections. First, the terminology of big data is examined. Second, an overview of how existing literature has discussed the application of big data in SCM context is provided. Finally, the SCM-process framework is related to big data as a potential area of application.

\subsection{The big data terminology}

Big data as a research field is multidisciplinary and relatively new. Big data is related to business intelligence and business analytics and has emerged as a separate concept, whereby structured data have become unstructured and mobile- and sensor-based technologies allow context-specific analysis [4]. From a management perspective, big data is a holistic approach for obtaining actionable insights to create a competitive advantage [10]. The technological component of big data is a prerequisite for its value generation for cases in which information systems are to cope with data collection, data management, and data utilization with the purposes of supporting business needs, deploying new business models, and improving existing processes [1]. Big data differs from business analytics in terms of the 5V's: volume, variety, velocity, veracity, and value [10].

For data collection, the characteristics of data have become more diverse and include various data formats like numbers, text, images, and audio [13]. Companies have been logging their transactions and activities resulting in large amounts of internal data. Combining this with the Internet of Things has enabled access to external data sources that can support the business even further, because it creates insights on the business environment at a more granular level [1]. Finally, the pace at which data are captured through advanced technologies, i.e., in real time, enables faster responses to changes as they occur [6].

For data management, the structured and unstructured data are to be stored in different systems in which a transparent IT-infrastructure enables data integrations and data sharing [9]. A knowledgediscovery process of data recording, data integration, data analysis, and data presentation are to be deployed and designed to support business purposes and decision-making [24]. Here various analytic techniques are to be applied, such as machine learning, data mining, and visualization methods [24]. Intra- and inter-organizational decision support systems rely on a network of systems for which governance procedures assure reliable data analytics [8].
For data utilization, knowledge discovered is either to support decision-making or to make automated decision-making [7]. The analytic insights derived can identify problems and opportunities within existing processes, discover explanatory and predictive patterns about what will happen and provide reasons why, and determine the best possible outcome between alternatives based on accumulated knowledge [36].

Ultimately, utilizing big data should increase performance outcomes that, from SCM perspective, can be measured as market, operational, and financial performance $[14,15,16]$.

\subsection{Big data applications in SCM}

The research domain of SCM is wide and contains several technical points of departures such as sourcing, operations management, logistics, finance, and IT. Many definitions of SCM exist, but for the purpose of the present paper we rely on the following definition provided by Stock and Boyer [32]: "The management of a network of relationships within a firm and between interdependent organizations and business units consisting of material suppliers, purchasing, production facilities, logistics, marketing, and related systems that facilitate the forward and reverse flow of materials, services, finances and information from the original producer to final customer with the benefits of adding value, maximizing profitability through efficiencies, and achieving customer satisfaction."

The application of big data in SCM has been referred to as SCM data science [35], predictive analytics [28], business analytics, big data analytics and supply chain analytics [36], which are principally similar terminologies for applying advanced qualitative and quantitative analytics for SCM purposes by utilizing the vast amount of fast moving and diversified data available. Overall, there are two distinct approaches of applying big data; it can either improve existing processes by focusing on current business needs and challenges, or data can be explored to create sellable products and services as new value propositions [34]. The potential of big data is not limited to manufacturing companies; retailers, service providers, healthcare professionals, and governments, among others, also see big data potential [10]. A survey of 145 responses shows that large service companies and their supply chains account for more employees and higher revenues than manufacturing companies; the service supply chains are therefore important to include for SCM theory building [29]. In this regard, the supply chain of both physical products and service deliveries can both benefit from big data.

On an overall supply chain level, a structured literature review demonstrates that big data can be 
applied in SCM for operational and development purposes, value discovery, value creation, and value capture [2]. Analytic applications are best utilized across the supply chain, where analytics operate crossfunctionally and as an integral part of company strategy [27]. In this context, Sanders [27] identifies source, make, move, and sell as primary areas of application for big data. For "source" big data may be used to segment suppliers, evaluate sourcing channel options, integrate with suppliers, and support supplier negotiations. For "make" it involves granular performance reporting, mitigation of capacity constraints, inventory optimization, facility location/layout, and workforce analytics. For "move" the application of big data involves routing, scheduling, using transportation alternatives, optimizing, and maintaining vehicles. Finally, for "sell" and marketing purposes, big data enables microsegmentation of customers, the capture and prediction of customer demand and behavior, and price and assortment optimizations. These applications are defined as conceptual, but also involve some empirical grounding. Furthermore, another literature review by Wang et al. [36] identifies the application of supply chain analytics in SCM as a strategic asset to be applied in several operational and strategic SCM processes. They establish a five-level analytic maturity framework for analytic applications in SCM. Level one and two are functional and process-based analytics that can be deployed in supply chain operations covering demand planning, procurement, production, inventory, and logistics. This involves, for example, aligning supply and customer demand at stock keeping unit level, increasing supply-chain visibility, managing and mitigating risks, managing real-time performance, and optimizing processes. Furthermore, collaborative, agile, and sustainable analytics as maturity level three, four, and five can be deployed in strategic SCM settings for strategic sourcing, supply-chain network design, and product design and development. This involves e.g. evaluation and selection of suppliers, the physical configuration of the supply chain, and to meet fluctuating demand requirements and utilizing market opportunities by having a rapid product design process. Further studies include the use of big data in the entire product life cycle from the beginning to end of life [17] and within human resources [35].

\subsection{A SCM process framework}

As an analytical framework for identifying applications of big data in SCM processes, the Supply Chain Operations Reference model (SCOR) has been chosen for this study. SCOR includes the crossfunctional, high-level, and generic processes plan, source, make, and deliver [31], return, which was added later. Previous studies have applied SCOR to evaluate applications of supply-chain analytics for strategic, tactical, and operational purposes, and argue that big data indeed have potential to make better decisions [30]. However, the application of big data in plan, source, make, deliver, and return has only partially been explored [27,36]. Also, SCOR has been used to determine business analytics and the required analytical supply chain process capabilities like analytic capabilities to plan and predict market trends of products and services [3]. Furthermore, SCOR has been used to determine the effect of business analytics on supply chain performance [22,33]. Given these previous studies, SCOR has been proved as a framework for assessing analytic applications in SCM. In addition, given the possibilities that big data have on service deliveries [10,23], the aspect of service processes has been added to the analytic framework and represents the view of service supply chain as well as service processes in manufacturing settings.

\section{Methodology}

Extant literature describes big data research within business environments as being in a nascent phase, during which exploratory and empirical studies are needed for its theoretical development [11,12]. In building new theory in an explorative manner, new constructs and/or relationships are to be discovered [5]. To fill the gap between SCM theory and SCM practices regarding big data and its applications, the Delphi study methodology was chosen due to its explorative nature. Linstone and Turoff [18] characterize the Delphi method as "a method for structuring a group communication process so that the process is effective in allowing a group of individuals, as a whole, to deal with a complex problem" [4]. The strength of the method is its ability to create consensus on an unexplored topic that lacks empirical evidence [25], which is the case of big data in SCM. The Delphi method can either be applied for the purpose of forecasting or conceptualizing [21]. With an end goal of ranking applications of big data in SCM, the method will be applied to identify the ways in which big data is used in supply chain processes. The study has followed the traditional Delphi study approach of design, selection of experts, data collection rounds of brainstorming, narrowing down of factors and ranking, and finally analysis [21]. Thus, with the ambition of reaching a more common understanding, an expert panel was created to provide new insights into this phenomenon.

In a Delphi study, recruitment of appropriate experts is essential for the validity of the results [26]. 
As big data seems to be most applicable in larger companies [11], the sampling criteria was that the experts had to have practical experience with and knowledge about supply chain processes, business analytics, and big data, as well as experience working with big data in one of the larger organizations in Denmark. Hence, the study was carried out in the Danish business environment. In addition, given that big data is expected to make an impact in several business environments, the aim was to have a diversified group of experts. Consequently, the sampling strategy was to ensure that experts come from a range of large Danish organizations, including manufacturers, wholesalers, retailers, and service providers, who all have different purposes in the supply chain. Specifically, when contacting the organizations, we asked for the person responsible for supply chain, IT, and/or big data. Furthermore, experts from universities and consultancies were also chosen as they have a more context-free understanding of big data compared to industry experts. Overall, the experts were not asked to evaluate current organizational practices, but instead asked to share their overall knowledge of the field. In total 67 companies were contacted and 24 experts agreed to participate, which is the sample size considered appropriate for a Delphi study under typical circumstances [37].

The Delphi study was designed as a three-round online questionnaire with two parts. The first part focused on understanding what characterizes big data in SCM, while the second part focused on exploring and empirically identifying possible areas of application for big data in SCM. Each Delphi round can have the purpose of brainstorming to identify dominant factors in a particular domain and/or to rank/prioritize a seeded list [37]. The first Delphi round contained both brainstorming and seeding. First, seeding procedures were applied using a five-point Likert scale to reach consensus on the terminology of big data in SCM context. This step drew on existing big data definitions and theory related to data collection, data management, data utilization, and performance as already elaborated in the literature section. Secondly, a brainstorming section about the areas of application for big data in supply chain processes took place based on the SCOR, as explained earlier in the literature section. Furthermore, information about the participants' education, expertise, and experience were collected in the first Delphi round. In the second Delphi round, the experts were asked to re-evaluate their responses based on the mean value achieved for each question in the first Delphi round regarding the understanding of big data in SCM. Also, the brainstorming responses for each SCOR process on how big data can be applied in SCM from the first Delphi round were condensed by the authors to four to eight statements and the experts were asked to rate on a five-point Likert scale. In the third and final Delphi round, they re-evaluated the application scores based on the mean values achieved in the second Delphi round.

\section{Findings}

This section presents the findings from the Delphi study, based on the responses given by the experts. This includes responses for the terminology of big data in SCM context and the areas of applications identified and ranked for big data in SCM.

\subsection{The big data terminology in SCM}

We questioned the respondents in regard to four aspects of the big data terminology. The questions asked, the mean values, and standard deviation (S.D.) can be seen in Table 1. Overall, the four aspects received a score higher than 4 , indicating that these are all considered important parts of big data in SCM, although the data collection (DAC) aspect was rated highest by the experts (mean score of 4.4). Here the respondents especially agree that big data in SCM involves different data sources, automated generation of data, and large amounts of data. In regard to the aspect of data management (DAM), the questions of cross-data and system analysis as well as advanced algorithms, tools, and applications for data analysis had the highest scores. The lowest rated statement for data management is that big data in SCM involves complex governance procedures. However, the answers revealed some disagreement on this statement. For data utilization (DAU), the questions achieved more or less equally distributed scores, although the statement of automated decision-making received the lowest scores. In addition, the data utilization scores reveal that the utilization of big data is more for operational purposes than strategic purposes. Lastly, performance (PER) statements were more or less evenly distributed. There are, however, indications that big data is more about improving operational- and market-based performance than improving financial performance measurements.

\subsection{Big data's application in SCM}

The brainstorming performed by the respondents on how big data may be applied in SCOR processes resulted in the identification of 39 potential areas of application of big data in SCM as listed in Table 2. Specifically, four to eight statements were provided for each process as defined by the SCOR ranging from the return (RET) process with only four to eight 
Table 1. Scores for the big data terminology in SCM

\begin{tabular}{|c|c|c|c|c|c|}
\hline \multirow{2}{*}{ Code } & \multirow{2}{*}{ Big data in SCM involves? } & \multicolumn{2}{|c|}{ First answers } & \multicolumn{2}{|c|}{ Second answers } \\
\hline & & Mean & S.D. & Mean & S.D. \\
\hline DAC & Data collection & 4.4 & .43 & 4.4 & .42 \\
\hline DAC1 & $\begin{array}{l}\text { Different data sources (e.g. product-, market-, supply chain- } \\
\text { and financial data)? }\end{array}$ & 4.7 & .54 & 4.8 & .42 \\
\hline DAC2 & $\begin{array}{l}\text { Automated technologies to collect data (e.g. sensors, RFID, } \\
\text { internet, GPS)? }\end{array}$ & 4.7 & .57 & 4.6 & .58 \\
\hline DAC3 & Large amounts of data? & 4.4 & .71 & 4.4 & .71 \\
\hline DAC4 & Different types of data (e.g. numbers, text, audio and video)? & 4.1 & .90 & 4.2 & .83 \\
\hline DAC5 & High speed collection of data (e.g. real time data)? & 4.1 & .90 & 4.0 & .88 \\
\hline DAM & Data management & 4.0 & .45 & 4.1 & .44 \\
\hline DAM1 & Cross data and cross system analysis? & 4.3 & .75 & 4.3 & .70 \\
\hline DAM2 & $\begin{array}{l}\text { Advanced algorithms, tools and applications for data analysis } \\
\text { (e.g. optimization-, statistical- and simulation software)? }\end{array}$ & 4.3 & .77 & 4.3 & .77 \\
\hline DAM3 & $\begin{array}{l}\text { Advanced visualization techniques to support decision- } \\
\text { making? }\end{array}$ & 4.1 & .75 & 4.1 & .75 \\
\hline DAM4 & $\begin{array}{l}\text { Advanced system infrastructure for data acquisition, data } \\
\text { storage and data access? }\end{array}$ & 4.1 & .77 & 4.1 & .75 \\
\hline DAM5 & $\begin{array}{l}\text { Establishing and maintaining an integrated data- and system } \\
\text { network? }\end{array}$ & 4.0 & .64 & 4.0 & .64 \\
\hline DAM6 & $\begin{array}{l}\text { Complex governance procedures of harmonizing, cleaning } \\
\text { and sharing of data? }\end{array}$ & 3.6 & 1.20 & 3.7 & 1.11 \\
\hline DAU & Data utilization & 4.1 & .47 & 4.1 & .48 \\
\hline DAU1 & $\begin{array}{l}\text { Determines optimal decision by utilizing accumulated } \\
\text { knowledge? }\end{array}$ & 4.1 & .63 & 4.2 & .58 \\
\hline DAU2 & IT-enabled processes for fact-driven decision-making? & 4.2 & .73 & 4.2 & .74 \\
\hline DAU3 & $\begin{array}{l}\text { Operational decision-making (e.g. short term, focus on } \\
\text { efficiency)? }\end{array}$ & 4.2 & .89 & 4.2 & .89 \\
\hline DAU4 & $\begin{array}{l}\text { Discovers explanatory and predictive patterns about what will } \\
\text { happen and reasons why so? }\end{array}$ & 4.2 & .95 & 4.2 & .95 \\
\hline DAU5 & $\begin{array}{l}\text { Identifies problems \& opportunities within existing processes } \\
\text { and functions? }\end{array}$ & 4.1 & .85 & 4.1 & .82 \\
\hline DAU6 & Supporting business processes with actionable insights? & 4.0 & .64 & 4.0 & .60 \\
\hline DAU7 & $\begin{array}{l}\text { Strategical decision-making (e.g. long term, focus on } \\
\text { effectiveness)? }\end{array}$ & 4.0 & .71 & 4.0 & .71 \\
\hline DAU8 & Automated decision systems? & 3.6 & .95 & 3.5 & .90 \\
\hline PER & Performance & 4.3 & .46 & 4.3 & .45 \\
\hline PER1 & $\begin{array}{l}\text { Improving operational performance (e.g. cost, quality, } \\
\text { flexibility and speed)? }\end{array}$ & 4.4 & .50 & 4.4 & .50 \\
\hline PER2 & $\begin{array}{l}\text { Improving market performance (e.g. meeting customer } \\
\text { needs)? }\end{array}$ & 4.4 & .66 & 4.4 & .66 \\
\hline PER3 & Improving financial performance (e.g. overall profitability)? & 4.1 & .69 & 4.2 & .65 \\
\hline
\end{tabular}

statements for service (SER) processes. The scores were distributed with service (SER) having the highest score, followed by return (RET), logistics (LOG), planning (PLA), sourcing (SOU), and manufacturing (MAN), in that order. For sourcing, big data will most likely be used as decision support for purchasing and information that can be utilized when negotiating with suppliers. For manufacturing, the respondents agreed that big data will have the greatest impact on identifying optimization possibilities, identifying root causes for manufacturing issues, as well as gaining insights to the manufacturing processes. For the application of big data in service, the respondents agree or strongly agree on all eight statements. The scores for service reveals that big data may especially be deployed to identify customer segments, gain customer insights, adjust/customize/develop service offerings, and to practice direct marketing. When it comes to logistics, the highest scores were assigned to the statement utilize big data for gaining logistical insights and to assess logistical performance. In planning, the scores show that big data will have the greatest impact 
on improving independent forecasting techniques and gaining insights about end-user consumption for existing products. Lastly, for return, big data will mainly enable learnings from customer complaints and the identification of root causes on defects (quality improvement).

The scores show rather similar mean scores when evaluating the SCM processes to which big data will be most applicable. In anticipation of these results, the respondents were asked to prioritize the different SCM processes in terms of which processes the application of big data would be most applicable. As Table 3 highlights, logistics (mean score of 5.3) had the highest score, which was then followed by service, planning, manufacturing, sourcing, and return processes (mean score of 1.4). These scores indicate that the mean values from Table 2, on a grouping level, are not fully consistent regarding the processes to which big data is most applicable. For example, return processes were initially scored as having greater importance than manufacturing and sourcing (Table 2), but when prioritized, return processes scored lowest (Table 3). Therefore, the prioritized list should be considered more reliable when evaluating on a group level.

\section{Discussion}

The discussion section will be centered on three subjects: The terminology of big data, big data applications in SCM, and their ranking and prioritization.

There seems to be some confusion regarding the terminology of big data, for which extant publications have used similar terms such as SCM data science, predictive analytics, business analytics, supply chain analytics, and big data analytics [27,28,35,36]. Variation in usage makes it difficult to identify what big data is and what it is not. We have obtained some guidance about how big data may be understood in SCM perspective by asking a group of experts how they perceive big data in relation to data collection, management, and utilization and how it is expected to impact various aspects of performance. The findings indicate that big data is more about data collection than data management or utilization, and big data is mostly focused on combining various datasets for cross-data and cross-system analysis. Overall, the scores for all statements are rather high, which could be an indication that big data is a term that incorporates terminologies like business analytics and business intelligence, but with additional perspectives. As pointed out by Wang et al. [36], companies need to build up analytic capabilities as a strategic asset to integrate the use of these analytic capabilities crossfunctionally. Our findings support that statement, as the experts have shown that big data are mostly related to data collection. This is an indication that companies have not yet been able to utilize their vast amount of data available, and, as a result, rate data management and utilization are having less importance when determining the terminology of big data. Moreover, companies are not fully aware of how to generate value from big data, which is an important aspect of the 5V's as mentioned earlier [10]. This hypothesis is reinforced as financial performance has been rated lower than operational and marked based performance. Therefore, barriers might be present for different aspects of data management and utilization. Furthermore, veracity also has less importance as the data management aspect of complex governance procedures of harmonizing, cleaning, and sharing of data received a lower score. Since the experts disagreed on this statement, data governance may be a prerequisite for big data but not an integral part of big data. Literature has suggested that big data can either support decision-making or it can enable automated decision-making [7]. According to the scores of statements regarding data management and utilization, emphasis is given to decision-making over automated decision-making, which received the lowest score. In contrast, advanced algorithms, tools, and applications for data analysis received a significant higher score, which indicates that the application of analytic techniques such as machine learning [24], have a low maturity level and that the validity of these algorithms are not significant enough to deploy automated decision-making.

Reviewing the answers for the application of big data in SCM processes shows differences between strategic and operational purposes. For example, big data in manufacturing is best utilized for identifying optimization possibilities, identifying root causes, and gaining process insights, all of which are strategic perspectives for driving developments. Moreover, supply chain design aspects were rated lower in our study. Other strategic processes are related to sourcing, service, planning, and return processes. On the other hand, logistics are oriented towards gaining operational insights for tracking movements, scheduling transportation routes, assessing its performance, and thereby informing customers on expected deliveries. Other operational processes are related to sourcing and planning. Comparing this finding with the strategic and operational processes identified by Wang et al. [36] shows that big data in a manufacturing setting is also about strategic decision-making, and the same goes for determining a demand and supply strategy in planning processes. In addition, several big data applications have been confirmed, like for sourcing, logistics, and planning processes. There are, however, some contributions such as a differentiation between 
Table 2. Scores for big data's application in SCM

\begin{tabular}{|c|c|c|c|c|c|}
\hline \multirow{2}{*}{ Code } & \multirow{2}{*}{ Big data's application is, especially, useful in? } & \multicolumn{2}{|c|}{ First answers } & \multicolumn{2}{|c|}{ Second answers } \\
\hline & & Mean & S.D. & Mean & S.D. \\
\hline SOU & Sourcing processes & 3.9 & .37 & 3.9 & .38 \\
\hline SOU1 & Decision support for purchasing? & 4.3 & .72 & 4.3 & .72 \\
\hline SOU2 & Providing information for supplier negotiations? & 4.1 & .57 & 4.1 & .57 \\
\hline SOU3 & Assessing supplier performance? & 3.9 & .70 & 3.9 & .66 \\
\hline SOU4 & Supplier integration and data sharing? & 3.9 & .73 & 3.9 & .70 \\
\hline SOU5 & $\begin{array}{l}\text { Identifying and evaluating sourcing options for products and } \\
\text { suppliers? }\end{array}$ & 3.6 & .76 & 3.7 & .65 \\
\hline SOU6 & Automated purchasing decisions? & 3.7 & 1.08 & 3.7 & 1.08 \\
\hline SOU7 & Benchmarking the sourcing process? & 3.6 & .59 & 3.6 & .59 \\
\hline MAN & Manufacturing processes & 3.9 & .46 & 3.9 & .46 \\
\hline MAN1 & Identifying optimization possibilities? & 4.4 & .50 & 4.4 & .50 \\
\hline MAN2 & Identifying root causes regarding manufacturing issues? & 4.1 & .54 & 4.1 & .54 \\
\hline MAN3 & Gaining insights about manufacturing processes? & 4.0 & .85 & 4.0 & .85 \\
\hline MAN4 & Assessing manufacturing performance? & 3.9 & .85 & 3.9 & .85 \\
\hline MAN5 & Digitalizing manufacturing processes? & 3.7 & .87 & 3.7 & .73 \\
\hline MAN6 & $\begin{array}{l}\text { Understanding manufacturing cost structures and product } \\
\text { profitability? }\end{array}$ & 3.7 & .99 & 3.7 & .99 \\
\hline MAN7 & Designing flexible manufacturing setups? & 3.4 & .68 & 3.3 & .67 \\
\hline SER & Service processes & 4.4 & .41 & 4.4 & .42 \\
\hline SER1 & Identifying customer segments? & 4.6 & .75 & 4.7 & .66 \\
\hline SER2 & Gaining customer insights? & 4.6 & .51 & 4.6 & .50 \\
\hline SER3 & Adjusting existing service offerings? & 4.4 & .51 & 4.4 & .51 \\
\hline SER4 & Customizing service offerings? & 4.4 & .51 & 4.4 & .51 \\
\hline SER5 & Practicing direct marketing to specific customers? & 4.4 & .68 & 4.4 & .68 \\
\hline SER6 & Developing new service offerings? & 4.3 & .57 & 4.3 & .57 \\
\hline SER7 & Learning from and reacting to customer assessments? & 4.1 & .77 & 4.1 & .77 \\
\hline SER8 & Supporting interaction with customers? & 4.1 & .77 & 4.1 & .79 \\
\hline LOG & Logistics processes & 4.1 & .47 & 4.1 & .48 \\
\hline LOG1 & $\begin{array}{l}\text { Gaining logistical insights (e.g. by tracking movement and } \\
\text { identifying waste)? }\end{array}$ & 4.4 & .51 & 4.4 & .51 \\
\hline LOG2 & Assessing logistical performance & 4.1 & .79 & 4.2 & .60 \\
\hline LOG3 & $\begin{array}{l}\text { Informing suppliers and customers on operational logistical } \\
\text { performance (e.g. delays)? }\end{array}$ & 4.2 & .70 & 4.1 & .67 \\
\hline LOG4 & Scheduling transportation (e.g. products and employees)? & 4.1 & .76 & 4.1 & .76 \\
\hline LOG5 & Designing logistics networks? & 3.9 & .72 & 3.9 & .72 \\
\hline LOG6 & Identifying and evaluating logistical options? & 4.0 & .89 & 3.9 & .85 \\
\hline PLA & Planning processes & 4.1 & .53 & 4.1 & .50 \\
\hline PLA1 & Forecasting independent demand (e.g. finished goods)? & 4.4 & .51 & 4.4 & .51 \\
\hline PLA2 & $\begin{array}{l}\text { Gaining insights about end-user consumption for existing } \\
\text { products? }\end{array}$ & 4.3 & .47 & 4.3 & .47 \\
\hline PLA3 & Determining appropriate demand and supply strategy? & 4.1 & .55 & 4.1 & .55 \\
\hline PLA4 & Assessing planning performance? & 4.1 & .77 & 4.1 & .77 \\
\hline PLA5 & Planning dependent demand (e.g. raw materials)? & 4.0 & .83 & 4.0 & .73 \\
\hline PLA6 & $\begin{array}{l}\text { Gaining insights about end-user consumption for new } \\
\text { product releases? }\end{array}$ & 3.9 & 1.02 & 4.0 & .92 \\
\hline PLA7 & Conducting scenario and contingency planning? & 3.8 & .94 & 3.8 & .86 \\
\hline RET & Return processes & 4.1 & .51 & 4.1 & .43 \\
\hline RET1 & Learning from customer complaints? & 4.3 & .64 & 4.4 & .59 \\
\hline RET2 & Identifying root causes for defects? & 4.2 & .95 & 4.3 & .87 \\
\hline RET3 & Predicting return rates? & 4.1 & .79 & 4.2 & .67 \\
\hline RET4 & Assessing return process performance? & 3.8 & .70 & 3.7 & .64 \\
\hline
\end{tabular}


Table 3. Prioritization of big data's application in SCM

\begin{tabular}{|c|l|c|c|c|c|}
\hline \multirow{2}{*}{ Code } & \multicolumn{2}{|c|}{ To which processes is big data most applicable? } & \multicolumn{2}{c|}{ First answers } & \multicolumn{3}{c|}{ Second answers } \\
\cline { 3 - 6 } & & Mean & S.D. & Mean & S.D. \\
\hline LOG & Logistics & 4.5 & 1.37 & 5.3 & 1.20 \\
\hline SER & Service & 4.3 & 1.68 & 4.7 & 1.20 \\
\hline PLA & Planning & 4.1 & 1.60 & 4.1 & .91 \\
\hline MAN & Manufacturing & 3.6 & 1.32 & 3.2 & .89 \\
\hline SOU & Sourcing & 2.9 & 1.42 & 2.2 & 1.18 \\
\hline RET & Return & 1.6 & .87 & 1.4 & .81 \\
\hline
\end{tabular}

Note: A score of 6 indicates that the respondents consider the application most important, whereas a score of 1 is least important.

dependent and independent forecasting in planning processes. Another comparison can be made to the framework of source, make, move, and sell [27], which is similar to the SCOR processes used in this study. Similar applications were identified, although with some additional findings, such as support for purchasing decisions and assessing supplier performance. For manufacturing, additional applications are manufacturing optimizations and root cause analysis. The logistics processes have more or less the same applications as identified in previous literature. Finally, the sell aspect has not been part of this study, but some comparison can be applied to planning and service processes, although these are not fully comparable.

A central contribution of this paper is the assessment of big data in the well-established SCM process framework SCOR, in which service and return processes are two newly identified areas of application in SCM. The added aspect of service processes in service SCM perspective has been proved valid as its statements received significantly high scores. Regarding the application of big data, this study shows that big data is focused to a larger degree on service than on typical manufacturing supply chain with physical products. Earlier studies have discovered service applications for big data, e.g., maintenance, customer service, and product support [17], but other service aspects have also been explored in this study. The data- and information-driven processes for service, logistics, and planning have been rated as most applicable to big data analytics in SCM, which indicates that an increasing focus is to be placed on service supply chains and information flows. Another central contribution is the ranking of statements on the terminology and applications. To date, these different terminologies and applications have been lacking empirical insights, and this ranking increases the understanding of how to perceive, understand, and apply big data in SCM. The overall ranking in Table 2 and Table 3 shows an inconsistency in identifying which SCM processes are most applicable for big data. An explanation could be that, even though specific applications have been rated high, they might not be the best applications in which to make big data investments. This ranking may also have the limitation of the experts' preferences.

Business analytics are related to big data, the applications of which were explored earlier in relation to the SCOR framework [3,30]. Similar applications have been identified for big data, business analytics, and supply chain analytics, with descriptive, predictive, and prescriptive practices. The differences between big data and business analytics and its application seems to be linked to the data integrated for knowledge generation. A combination of the V's volume, variety, and velocity has been proved for the big data concept, which is not considered for the definition of business analytics [3]. Aspects of cross-data and system analysis and the use of advanced algorithms also make the application of big data different. The complexity of generating actionable knowledge is, therefore, greater when deploying big data methods rather than business analytics.

Although this study has identified several new areas of application, the applications listed should not be considered exhaustive. The Delphi approach has been guided by brainstorming and not by existing literature. For instance, some application areas related to sell, e.g., prize optimizations, were not identified [27]. Furthermore, the aspects of supply chain network design and decisions on the supply chain infrastructure [36] had very limited focus in our study. Aspects related to product life cycle were not fully identified, e.g., utility and maintenance aspects, and nor were product recovery decisions [17]. These missing, yet important, applications were not identified in our study, which indicate that the field of big data in SCM still is evolving and that many opportunities for utilizing big data exist.

\section{Conclusion}

This study has deployed an explorative Delphi study approach to provide a more thorough understanding of big data from SCM perspective by assessing and ranking the terminology of big data and exploring its application in SCM processes. A total of 
22 statements on the terminology of big data and, by using an adjusted SCOR framework, 39 applications for big data in SCM have been identified and ranked. The findings reveal that big data is more about data collection than data management and utilization, and that service, logistics and planning processes are more applicable processes for adapting big data applications than manufacturing, sourcing, and return processes.

Extant research has lacked empirical contributions; therefore, a central contribution of this paper is that the findings are empirically based. Additionally, ranking procedures have identified how big data is understood from a practical point of view regarding how big data could most likely be applied in SCM processes. The study has both confirmed previously identified applications and determined new applications, specifically within service and return processes. A further contribution is that big data and business analytics have similar applications for SCM purposes, a comparison from which the theoretical advances of big data can benefit. But the difference between the terminologies relies on the data integration of the V's volume, variety, and velocity, which makes big data significantly more complex to generate actionable insights.

The practical implications for this study give guidance to SCM practitioners on which opportunities to explore in the application of big data in SCM. Much has been written about the potential of big data, but limited guidance has been given regarding ways in which practitioners can utilize, generate, and capture the value of big data. These ranked applications provide initial guidance to practitioners, and the authors hope that they can help practitioners to deploy successful big data initiatives. The theoretical implications add additional perspectives to how big data is understood and where it may be applied, and, as existing work has been rather fragmented [11,36], this is an important contribution to the theoretical development.

\section{Future research}

Based on the discussion above, there are still important questions that need to be answered concerning big data from SCM perspective. First of all, this and other studies have been explorative and have focused on establishing an overview of various applications. This broad approach should change to one that is more in-depth, for which the different applications of big data in SCM need to be understood at a more granular level. For instance, this study does not specifically point at problem areas that may be solved through big data analytics or how it may impact and benefit SCM practices. Consequently, a bottom-up approach such as case study, expert interview, or another explorative approach that studies real-life contexts would be a valuable research methodology to better understand how big data analytics are being deployed and used in different industry settings. Specifically, research questions on service and logistics processes in service companies and manufacturing companies that have a service strategy would be valuable research themes as they are rated as the most valid applications in this study. The application of business analytics seems to have similarities to big data, which could be subject of further investigation, thereby incorporating business analytic theory into big data theory building. Also, as this study has an explicit focus on big data in SCM, further research is needed to fully understand the differences between business analytics, supply chain analytics, and big data analytics. In addition, it is a limitation that this study only includes Danish experts. Therefore, we encourage conducting studies in other national contexts to compare findings. Furthermore, potential research could be interdisciplinary, in which SCM and statistical researchers work together on understanding the different analytic techniques that could be deployed for different SCM purposes and applications. In other words, it has been emphasized that organizations need interdisciplinary skills in data scientists [35]. The same is needed for the research community.

\section{References}

[1] $\mathrm{Bi}, \mathrm{Z}$. and Cochran, D. Big data analytics with applications. Journal of Management Analytics 1(4), 2014, pp. 249-265.

[2] Brinch, M. Big data and supply chain management: A content-based literature review. The 23rd EurOMA conference, EurOMA, Trondheim, 2016.

[3] Chae, K.B. and Olson, D.L. Business analytics for supply chain: A dynamic-capabilities framework. International Journal of Information Technology \& Decision Making 12(1), 2013, pp. 9-26.

[4] Chen, H., Chiang, R.H.L., and Storey, V.C. Business intelligence and analytics: From big data to big impact. MIS quarterly 36(4), 2012, pp. 1165-1188.

[5] Colquitt, J.A. and Zapata-Phelan, C.P. Trends in theory building and theory testing: A five-decade study of the "Academy of Management Journal." The Academy of Management Journal 50(6),2007, pp. 1281-1303.

[6] Davenport, T.H., Barth, P., and Bean, R. How 'big data' is different. MIT Sloan Management Review 54(1), 2012, pp. 22-24

[7] Davenport, T.H. and Kirby, J. Just how smart are smart machines? MIT Sloan Management Review 57(3) ,2016, pp. 20-25.

[8] Demirkan, H. and Delen, D. Leveraging the capabilities of service-oriented decision support systems: Putting analytics and big data in cloud. Decision Support Systems 55(1), 2013, pp. 412-421. 
[9] Duan, L. and Xiong, Y. Big data analytics and business analytics. Journal of Management Analytics 2(1), 2015, pp. 1-21.

[10] Fosso Wamba, S., Akter, S., Edwards, A., Chopin, G., and Gnanzou, D. How 'big data' can make big impact: Findings from a systematic review and a longitudinal case study. International Journal of Production Economics 165, 2015, pp. 234-246.

[11] Frizzo-Barker, J., Chow-White, P.A., Mozafari, M., and Ha, D. An empirical study of the rise of big data in business scholarship. International Journal of Information Management 36(3), 2016, pp. 403-413.

[12] George, G., Haas, M.R., and Pentland, A. Big Data and Management. Academy of Management Journal 57(2),2014, pp. 321-326.

[13] Goes, P.B. Big Data and IS Research. MIS Quarterly 38(3), 2014, pp. 3-8.

[14] Golicic, S.L. and Smith, C.D. A meta-analysis of environmentally sustainable supply chain management practices and firm performance. Journal of Supply Chain Management 49(2), 2013, pp. 78-95.

[15] Gunasekaran, A. and Kobu, B. Performance measures and metrics in logistics and supply chain management: a review of recent literature (1995-2004) for research and applications. International Journal of Production Research 45(12), 2007, pp. 2819-2840.

[16] Hult, G.T., Ketchen, D.J., Griffith, D.A., et al. An assessment of the measurement of performance in international business research. Journal of International Business Studies 39(6), 2008, pp. 1064-1080.

[17] Li, J., Tao, F., Cheng, Y., and Zhao, L. Big Data in product lifecycle management. The International Journal of Advanced Manufacturing Technology 81, 2015, pp. 667-684.

[18] Linstone, H.A. and Turoff, M. The Delphi Method Techniques and applications. New Jersey Insitute of Technology, New Jersey, 2002.

[19] Manyika, J., Chui, M., Bughin, J., Dobbs, R., Bisson, P., and Marrs. Disruptive technologies: Advances that will transform life, business, and the global economy. McKinsey Global Insitute, (2013).

[20] Mortenson, M.J., Doherty, N.F., and Robinson, S. Operational research from taylorism to terabytes: A research agenda for the analytics age. European Journal of Operational Research 241, 2015, pp. 583-595.

[21] Okoli, C. and Pawlowski, S.D. The Delphi method as a research tool: an example, design considerations and applications. Information \& Management 42(1), 2004, pp. $15-29$.

[22] Oliveira, M.P.V. de, McCormack, K., and Trkman, P. Business analytics in supply chains - The contingent effect of business process maturity. Expert Systems with Applications 39, 2012, pp. 5488-5498.

[23] Opresnik, D. and Taisch, M. The value of big data in servitization. International Journal of Production Economics 165, 2015, pp. 174-184.

[24] Philip Chen, C.L. and Zhang, C.-Y. Data-intensive applications, challenges, techniques and technologies: A survey on Big Data. Information Sciences 275, 2014, pp. 314-347.

[25] Powell, C. The Delphi technique: myths and realities. Methodological Issues in Nursing Research 41(4),
2003, pp. 376-382.

[26] Rowe, G. and Wright, G. The Delphi technique: Past, present, and future prospects - Introduction to the special issue. Technological Forecasting and Social Change 78(9), 2011, pp. 1487-1490.

[27] Sanders, N.R. How to use big data to drive your supply chain. California Management Review 58(3), 2016, pp. 26-48.

[28] Schoenherr, T. and Speier-Pero, C. Data science, predictive analytics, and big data in supply chain management: Current state and future potential. Journal of Business Logistics 36(1), 2015, pp. 120-132.

[29] Sengupta, K., Heiser, D., and Cook, L. Manufacturing and service supply chain performance: A comparative analysis. Journal of Supply Chain Management 42(4), 2006, pp. 4-15.

[30] Souza, G.C. Supply chain analytics. Business Horizons 57, 2014, pp. 595-605.

[31] Stewart, G. Supply-chain operations reference model (SCOR): the first cross-industry framework for integrated supply-chain management. Logistics Information Management 10(2), 1997, pp. 62-67.

[32] Stock, J.R. and Boyer, S.L. Developing a consensus definition of supply chain management: a qualitative study. International Journal of Physical Distribution \& Logistics Management 39(8), 2009, pp. 690-711.

[33] Trkman, P., McCormack, K., de Oliveira, M.P.V., and Ladeira, M.B. The impact of business analytics on supply chain performance. Decision Support Systems 49, 2010, pp. 318-327.

[34] Vanauer, M., Bohle, C., and Hellingrath, B. Guiding the introduction of big data in organizations: A methodology with business- and data-driven ideation and enterprise architecture management-based implementation. Proceedings of the 48th Hawaii International Conference on System Sciences, IEEE, 2015, pp. 908-917.

[35] Waller, M.A. and Fawcett, S.E. Data science , predictive analytics, and big data: A revolution that will transform supply chain design and management. Journal of Business Logistics 34(2), 2013, pp. 77-84.

[36] Wang, G., Gunasekaran, A., Ngai, E.W.T., and Papadopoulos, T. Big data analytics in logistics and supply chain management: Certain investigations for research and applications. International Journal of Production Economics 176, 2016, pp. 98-110.

[37] Worrell, J.L., Di Gangi, P.M., and Bush, A.A. Exploring the use of the Delphi method in accounting information systems research. International Journal of Accounting Information Systems 14(3), 2013, pp. 193-208.

[38] Zailani, S.H., Subaramaniam, K.S., Iranmanesh, M., and Shaharudin, M.R. A global exploration of big data in the supply chain. International Journal of Physical Distribution \& Logistics Management 46(8), 2016, pp. 710-739. 